\title{
形状特徵の重ね合わせによる個体別手指モデルの生成*
}

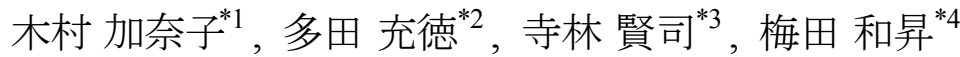

\section{Synthesis of Subject-Specific Finger Model by Superimposition of Geometric Features}

\author{
Kanako KIMURA*1, Mitsunori TADA, Kenji TERABAYASHI and Kazunori UMEDA \\ ${ }^{* 1}$ Course of Precision Engineering, School of Science and Engineering, Chuo University \\ 1-13-27 Kasuga, Bunkyo-ku, Tokyo, 112-8551 Japan
}

In this paper, we propose a method to synthesize subject-specific three dimensional finger models including skin and bones from geometric database and representative dimensions that can be measured by a caliper. The geometric database necessary for our method was developed by analyzing principal feature of the individual differences by using principal component analysis. The proposed method synthesizes subject-specific models by blending these principal features. The weight for each feature was determined by numerical optimization so that the synthesized subject-specific model reproduces the representative dimensions of the actual subject. We applied our method to fifty fingers. The average of the maximum error was $1.0 \mathrm{~mm}$, while the average error was $0.2 \mathrm{~mm}$. For more than $70 \%$ of the subjects, the bone as well as skin geometry were synthesized with acceptable error range from the representative dimensions of surface geometry. As for the remaining 30\%, there was significant error in bone length. This method has distinct advantage over the conventional method in which time consuming manual segmentation for medical images is necessary, since we can generate subject-specific finger models in 5 to 10 minutes automatic computation.

Key Words : Subject-Specific Model, Individual Difference, Principal Component Analysis, Non-Rigid Volume Registration

\section{1. 緒}

人体のバイオメカニカルな機能のシミュレーションには，個体別モデルが不可欠である．なぜなら，シミュレー ション結果の妥当性を検証するには，ある個人に対して得られた実験結果とその被験者を再現したモデルを用い た解析結果を比較する必要があるからである。本稿では，ノギスのような簡便な道具で計測できる代表寸法值か ら形状特徵を重㸚合わせ，骨まで含んだ個体別 3 次元手指モデルを生成する手法を提案する.

人体の個体別モデルを作成するには，対象部位の 3 次元医用画像の撮像，医用画像のセグメンテーション，そ してセグメント毎の表面形状抽出のように時間を要する作業を避けることができない．このため，従来よりこれ ら一連の作業を効率化するための研究が行われてきた.

これを実現するための方法の 1 つに閾值処理 ${ }^{(1)}$ や動的輪郭モデル(2)(3)を用いたセグメンテーションの自動化があ る. しかし, 撮像装置, 撮像シーケンス, そして撮像部位の違いがセグメンテーションの精度に影響を与えるた め, 自動化するためには試行錯誤的なパラメータチューニングが必要となる.

この問題に対するもう 1 つのアプローチが，テンプレートモデルを用いる手法である(4) (6).この手法では，基 準となるテンプレートモデルを多自由度に変形することで異なる被験者の形状を再現する。変形量については，2 つのデータを位置合わせすることで計算する。例えば，テンプレートモデルを対象となる被験者のポイントクラ ウドやMRI 画像へと位置合わせする手法 ${ }^{(4)(5)}$ ，テンプレートMRI 画像を対象となる被験者の MRI 画像へ位置合

* 原稿受付 2011 年 10 月 14 日

*1 中央大学大学院理工学研究科精密工学専攻

（干112-8551 東京都文京区春日 1-13-27）

*2 正員, (独) 産業技術総合研究所デジタルヒューマン工学研究センター

（广135-0064 東京都江東区青海 2-3-26）

*3 正員, 中央大学大学院理工学研究科精密工学専攻

${ }^{* 4}$ 正員, フェロー, 中央大学大学院理工学研究科精密工学専攻

E-mail: kimura@sensor.mech.chuo-u.ac.jp 


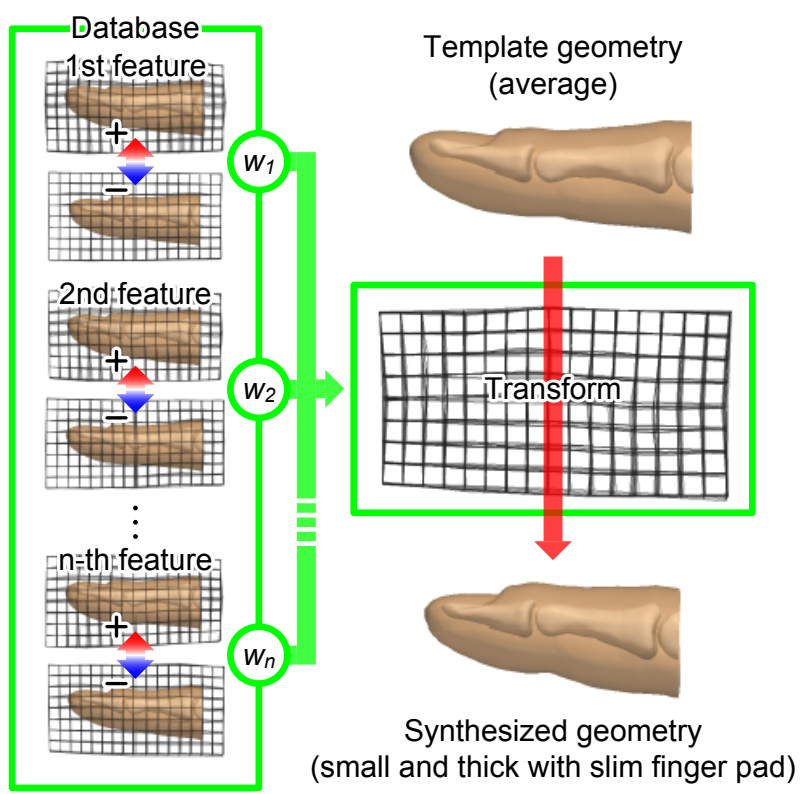

Fig. 1 Synthesizing finger geometry from database.

わせする手法 ${ }^{(6)}$ などが提案されている。これらの手法では明示的なセグメンテーションが必要ない。しかし，対象 となる被験者の医用画像は依然として撮像する必要がある。

特徵に重みをつけて重㸚わせるだけで，様々な形状を生成できる(7)という点が，データベースを用いた手法 ${ }^{(8)(9)}$ の利点である。この手法は代表寸法に基づく頭部有限要素モデルの生成にも応用されている ${ }^{(10)}$.この研究で は，計測した代表寸法とデータベースから生成したモデルの代表寸法の誤差が最小になるように各特徵に対する 重みを決定することで，個体別頭部モデルを生成した。しかし，頭部表面形状に対して構築したデータベースを 用いて頭骨や脳のような内部組織の形状を生成したにも関わらず，それらの再現精度については厳密な検証が行 われていない.

筆者らは，非剛体ボリュームレジストレーションを用いて手指の MRI 画像から内部構造の形状まで含めた個体 差を計測する手法と, それらを統計的に分析し形状特徵データベースを構築する手法を提案した ${ }^{(1)}$. 本稿では, こ のデータベースに含まれる形状特徵の重㸚合わせによる形状生成手法を提案すると共に，内部構造の形状まで含 めた再現精度の検証を行う。なお，本研究では工業製品の検証への応用を想定し，正規分布の $2 \sigma$ 内に存在し得る 形状を持つ個体別モデルを生成の対象とする.

\section{2. 方法}

\section{$2 \cdot 1$ 概要}

ノギスで計測可能な代表寸法から形状特徴の重みを決定し，それらを重ね合わせる事でその被験者の 3 次元手 指モデルを生成することが本研究の目的である. 図 1 に示す通り, 形状特徵の重み付き線形和を用いて正規分布の $2 \sigma$ 内に存在し得る形状を生成する技術が提案手法のベースとなる。この技術では形状特徴が変位場で表される. それゆえそれらの重み付き線形和も変位場であり，それに従い平均形状を変形すれば様々な形状特徵を有する手 指モデルが迅速に生成できる。個体別モデルを生成するためには各特徵に対する重みを適切に設定する必要があ るが，本研究では (10) と同様に対象となる被験者の代表寸法が可観測であることを利用する。すなわち実際に計 測した代表寸法と生成したモデルの代表寸法の誤差が最小になるように数值最適化手法を用いて重みを決定する.

\section{$2 \cdot 2$ データベース}

本研究では筆者らが過去に構築したデータベースを利用する。このデータベースとは，50人分の成人男性右手 示指の MRI 画像から計算した個体差の主成分すなわち，特徵である。個体差の計算には非剛体ボリュームレジス トレーションを用いた。それゆえ形状の個体差が画像中に等間隔に配置した制御点におけるべクトルの集合，つ 


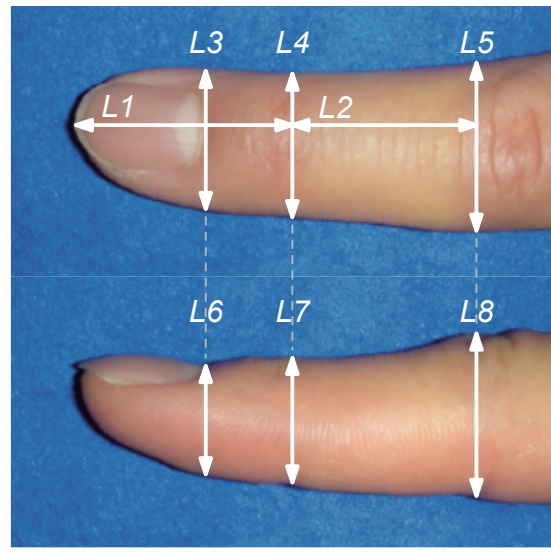

Fig. 2 Eight representative dimensions of an index finger.

まり変位場で表される。また，医用画像を対象とするため皮膚表面の形状だけでなく，骨のような内部構造の個 体差についても考慮できる. 非剛体ボリュームレジストレーションやデータベース構築の詳細については (11)を 参照されたい.

なお，詳しくは $3 \cdot 2$ で述べるが，本研究で利用したデータベースは (11) と同一ではない. 形状の再現精度を厳 密に評価するために，生成の対象となる被験者を除いた 49 名分の個体差からデータベースを再構成した.

\section{$2 \cdot 3$ 最適化}

実際にノギスで計測した代表寸法と生成したモデルの代表寸法の誤差を最小化するために数值最適化手法を導 入する. 最適化のための目的関数 $e(\boldsymbol{w})$ については式(1)に示す通り, 代表寸法の誤差に関する第 1 項と, 最適化 により求められる重みの範囲を制限するためのペナルティに関する第 2 項から構成する.

$$
e(\boldsymbol{w})=\sum_{i=1}^{m}\left(L_{i}-l_{i}(\boldsymbol{w})\right)^{2}+\sum_{j=1}^{n} c_{j}\left(\frac{w_{j}}{2 \sigma_{j}}\right)^{2}
$$

ただし， $\boldsymbol{w}=\left(w_{1}, w_{2}, \cdots, w_{n}\right)$ が重みを，第 1 項の $m$ が代表寸法数を， $L_{i}$ がノギスで計測した $i$ 番目の代表寸法を， $l_{i}(\boldsymbol{w})$ が生成したモデルの $i$ 番目の代表寸法を表す．また，第 2 項の $n$ が生成に用いる主成分数を， $\sigma_{j}$ がデータベー スに含まれる全ての被験者の $j$ 番目の主成分得点の標準偏差を, $c_{j}$ が $j$ 番目の主成分のペナルティの寄与を表す.

主成分得点の標準偏差についてはデータベースを構築する際に計算した。すなわち，データベースに属する被 験者を主成分の線形和で表した時の各主成分の得点を計算し, $j$ 番目の主成分得点の標準偏差を $\sigma_{j}$ とした. なお, 主成分得点 $c_{j}$ と重み $\boldsymbol{w}$ はどちらもデータベース中の主成分に対する係数である事に変わりはない. しかし，本稿 ではそれらが主成分分析時に得られた既知の值であるのか，あるいは本手法で最適化により求める值であるのか を区別するために，前者を「主成分得点」と，後者を「重み」と表現している．形状のばらつきが正規分布に従う と仮定すると $-2 \sigma$ から $2 \sigma$ の間に約 $95 \%$ の被験者が存在することになる. ペナルティ項を導入することで, 統計 的に存在する確率が低い過大，もしくは過小な重みへの最適化を抑制できる。また，主成分により主成分得点の 範囲が異なるが，その違いがペナルティ項の寄与に与える影響を規格化するために求める重みをその標準偏差で

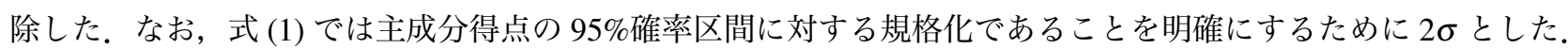

\section{3. 実験}

\section{$3 \cdot 1$ 被験者と代表寸法の計測}

データベースに属する 50 名の成人男性を代表寸法の計測と提案手法を用いた形状モデルの生成対象とした。た だし，今回はノギスを使用した実測ではなく，各被験者の MRI画像をもとに別途作成した形状モデルから代表寸 法に相当する長さをコンピュータ上で計測した．また，このモデルと生成したモデルを比較することで形状の再 現精度を検証した。代表寸法の計測箇所を図 2 に示す。計測の明瞭さや簡便性を考慮し，これら 8 箇所を代表寸 


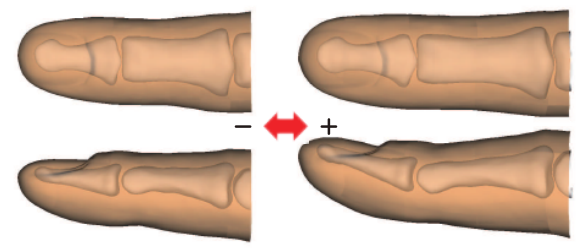

(a) Finger dimension (1st feature)

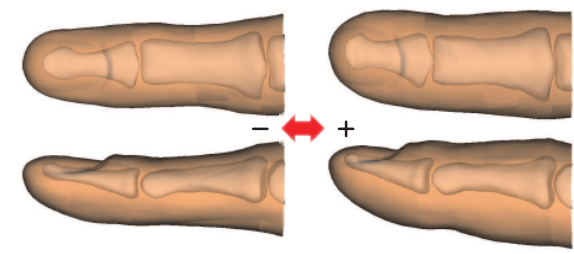

(b) Finger thickness (5th feature)

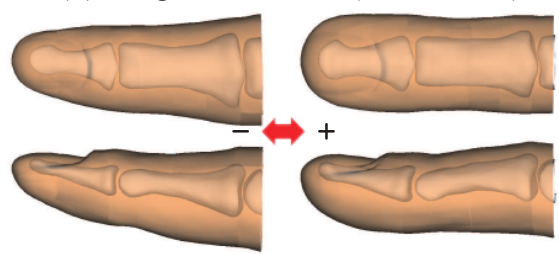

(c) Finger pad thickness (6th feature)

Fig. 3 First, fifth and sixth principal feature of an index finger.

法とした． $L_{1}$ と $L_{2}$ が関節長， $L_{4}$ と $L_{5}$ が関節幅， $L_{7}$ と $L_{8}$ が関節厚みを表す．また $L_{3}$ と $L_{6}$ についてはそれぞれ 爪根元における手指の幅と厚みとした。このような顕著な外形特徵に基づく寸法であれば，被験者に関わらず計 測部位を容易に特定することが可能であり，結果として計測の再現性を高めることができる.

\section{$3 \cdot 2$ データベース}

本稿では 1 から 10 番目に顕著な手指の特徵をモデルの生成に使用した。ただし，ここで使用したデータベース とは，生成の対象となる被験者を除いた 49 名分の個体差に対して再構築したものである．モデルの生成に用いる データベースからその対象となる被験者の情報を排除することで，提案手法の妥当性を正当に評価できる．使用 する主成分の数が再現性に与える影響については $5 \cdot 2 て ゙$ 考察する.

図 3 に特徵の一例を示す．例えば (a) が手指の大きさに対応する第 1 主成分，(b) が手指の太さに対応する第 5 主成分, そして (c) が指腹の厚さに対応する第 6 主成分を表す。重みを正負に変化させることでそれぞれの特徵の 強弱を連続的に変化させることができる，このような特徵以外にも末節骨と中節骨の骨長の比や，手指の曲がり に対応する主成分があることが明らかになっている(11).

\section{$3 \cdot 3$ 最適化}

式 (1)で定義した目的関数の最小化には, 導関数の明示的な計算が必要ない滑降シンプレックス法を用いた. 本 稿で行った実験における目的関数を式 (2)に再揭する.

$$
e(\boldsymbol{w})=\sum_{i=1}^{8}\left(L_{i}-l_{i}(\boldsymbol{w})\right)^{2}+\sum_{j=1}^{10} 0.05\left(\frac{w_{j}}{2 \sigma_{j}}\right)^{2}
$$

前述の通り第 1 項が計 8 箇所で計測した代表寸法誤差の 2 乗和, 第 2 項が求める重みの範囲を制限するためのぺナ

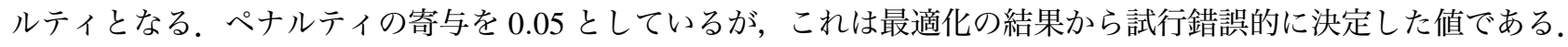

最適化を行うには初期值と収束条件の設定が重要である. 本最適化では 10 次元空間の原点と, 乱数を用いて生 成した 10 点を用いて初期シンプレックスを構成した。ただし $j$ 番目の重みに対応するシンプレックスの值につい ては $-2 \sigma_{j}$ から $2 \sigma_{j}$ を乱数の生成範囲とした。 また, シンプレックスを構成する各点に拈ける目的関数值の最大の 比が $1.0 \times 10^{-5}$ より小さくなるか, 反復回数が $1.0 \times 10^{4}$ を越えた時に最適化を終了した. 


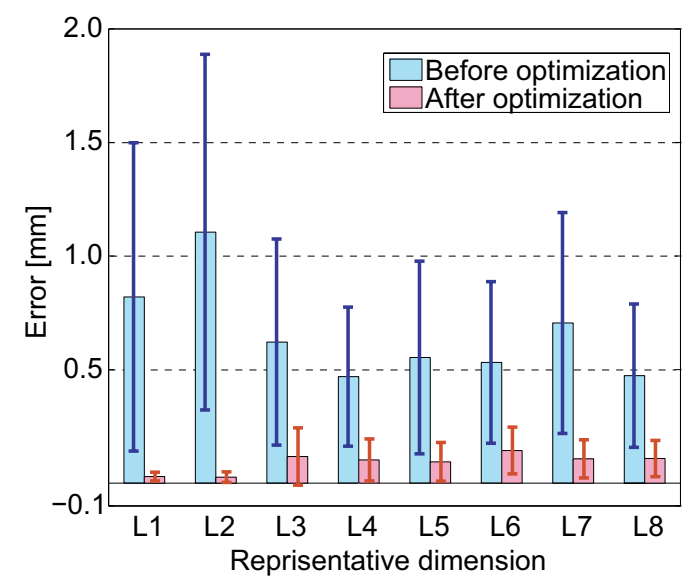

Fig. 4 Average errors and standard deviation of the representative dimensions before and after optimization for all subjects.

\section{4. 結 果}

\section{$4 \cdot 1$ 最適化とその安定性}

2.4GHz の Intel Core 2 Duo プロセッサと 4G バイトのメモリを搭載したコンピュータで最適化を実施した．被験 者と初期シンプレックスにも依存するが，おおむね 5 から 10 分程度で最適化が完了した．同一被験者に対して異 なる初期条件で最適化を実施してもほぼ同一の重みへと収束した。また，全ての被験者において関数值の最大の 比が既定値よりも小さくなったために最適化が終了した，以上より，最適解が一意に計算できたことが分かる.

\section{$4 \cdot 2$ 代表寸法に関する比較}

計測した代表寸法と，提案手法で生成したモデルの代表寸法を比較した，最適化前後における全ての被験者に 対する代表寸法誤差の平均と標準偏差を図 4 に示す。最適化前には平均 0.5 から $1.0 \mathrm{~mm}$ 程度あった誤差が, 最適 化を実施することで 0.04 から $0.14 \mathrm{~mm}$ にまで減少することが分かる.

\section{$4 \cdot 3$ 形状に関する比較}

別途各被験者の MRI 画像から作成したモデルと，提案手法で生成したモデルを比較することで形状の一致度を 検証した，比較に先立ち，双方の距離が最小になるように，形状処理ソフトウェア (Geomagic 7, Geomagic, Inc.) の剛体レジストレーション機能を用いて後者を前者へと位置合わせした。これは最小化できるのがあくまで代表 寸法の誤差であり，モデル全体の剛体変位については一切考慮できないからである.

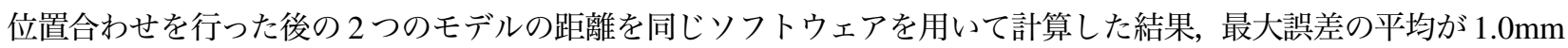
程度, 平均誤差の平均が $0.2 \mathrm{~mm}$ 程度となった。これは MRI 画像に対する非剛体レジストレーションを用いた個体 別モデルの自動生成手法 ${ }^{(11)}$ と同程度の再現精度である.MRI 画像に比べると代表寸法が持つ情報量は極端に少な いが，データベースを用いてこれを補完することでMRI 画像を用いた場合と同程度の精度で形状復元が実現でき た.

\section{5. 考察}

\section{$5 \cdot 1$ ペナルティ項の有効性}

目的関数におけるペナルティ項の働きについて考察する. 図 5 にペナルティ項が無い場合と有る場合の第 1 主 成分と第 2 主成分の重みの分布と主成分得点の 2 標準偏差区間 (95\%確率棈円) を示す.

$2 \cdot 3$ で述べたように，形状のばらつきが正規分布に従うと仮定すると $-2 \sigma$ から $2 \sigma$ の間に約 $95 \%$ の被験者が存 在する。ペナルティ項を評価関数に導入せずに最適化を行った場合, 代表寸法の誤差は最小化されるものの重みの 


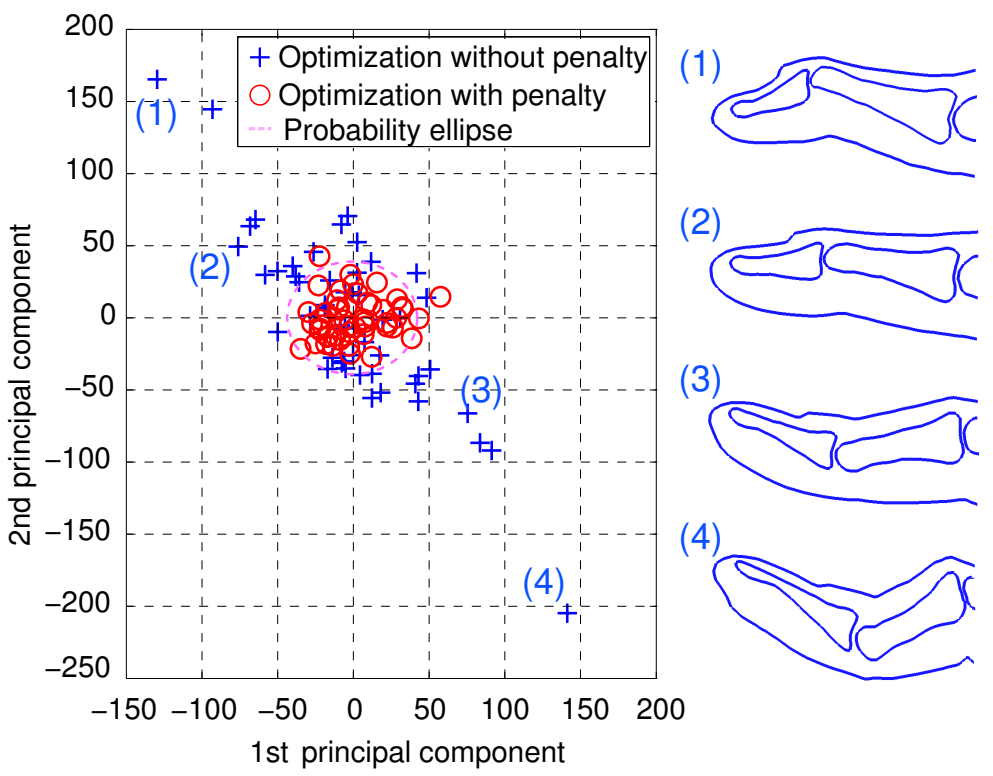

Fig. 5 Distribution of the computed weights for the 1 st and 2 nd principal components when two different objective function with and without the penalty term were employed.

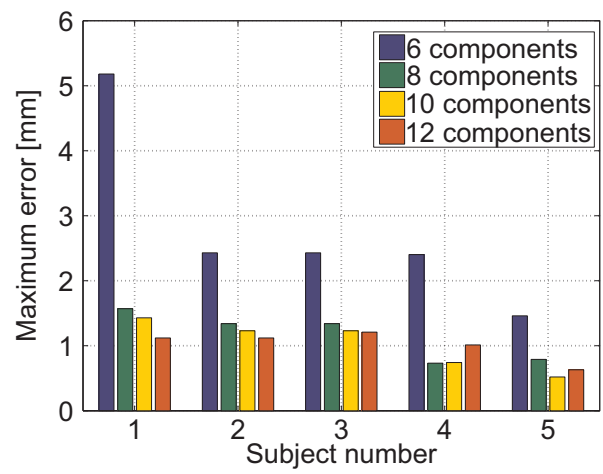

Fig. 6 Maximum error accoding to the number of the principal components.

多くは 95\%確率棈円から大きく外机值へと収束した。結果として図 5 の (1) から (4)のように過度に屈曲，もし くは伸展したモデルが生成された。一方ペナルティ項を導入した場合, 多くの重みを統計的に考えて妥当な值へと 収束させることが出来た。このようにペナルティ項の導入は, 形状詋差を減少させるのに有効である．第 3 から 第 10 主成分についてもこの図と同様にペナルテイ項によって過大な重みへの最適化が抑制される事を確認した.

\section{$5 \cdot 2$ 主成分の数が再現精度に与える影響}

最適化に用いる主成分の数が形状の再現性に与える影響を調べる。最適化に用いる主成分数を $6 ， 8 ， 10 ， 12$ と 変化させた条件でモデルを生成し, 形状の再現精度の比較を行った。典型的な結果が現れた 5 人の被験者につい て主成分数毎の最大詋差を図 6 に, 平均形状誤差を図 7 に示す.

上位 6 主成分を用いた場合，生成されるモデルの誤差は非常に大きいが，8 主成分を用いる事でその誤差が大幅 に減少し，10，12 主成分では誤差の減少がほぼ一定に留まる事がわかる。一方で上位 10 主成分まではおおむね 5 分から 10 分程度で重みの最適化が完了するのに対し，上位 12 主成分を利用した場合，最適化の完了まで 20 から 30 分の時間を要する事がわかった。これらの結果から再現性と計算コストとの兼ね合いを考慮し，上位 10 主成分 までを生成に用いる事が妥当であると判断した。 


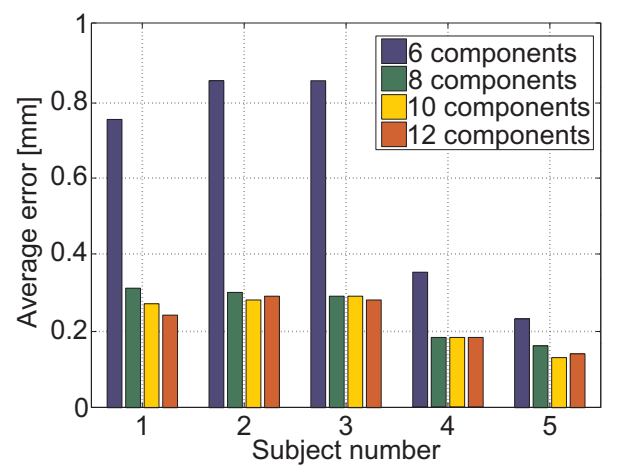

Fig. 7 Average error accoding to the number of the principal components.

- Synthesized from database - Created from MRI images

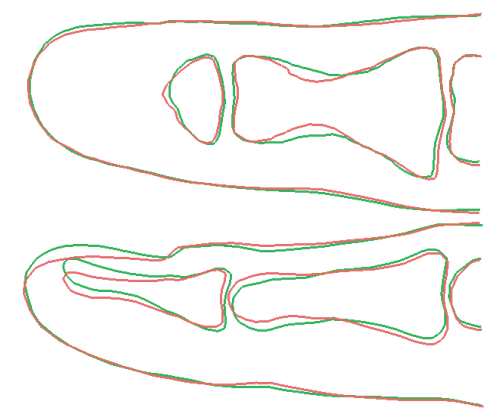

(c) Error in nail (10\%)

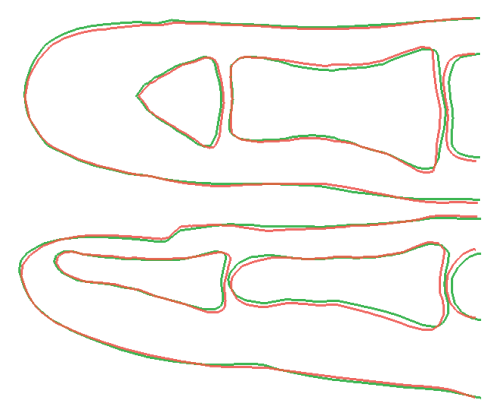

(a) Small error $(64 \%)$

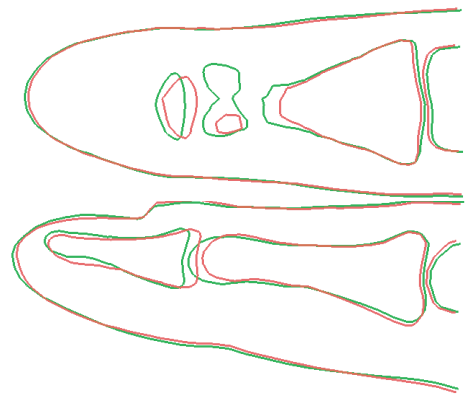

(d) Error in DIP joint (10\%)

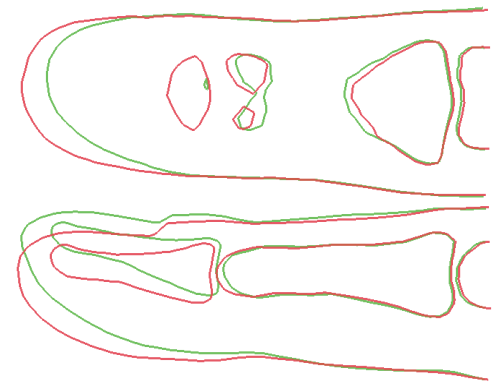

(b) Error caused by posture (8\%)

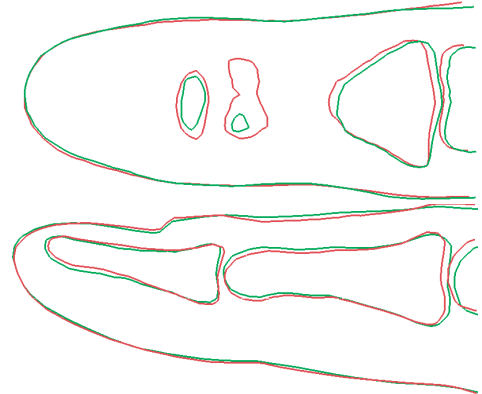

(e) Error in PIP joint (8\%)

Fig. 8 Comparing two finger geometries synthesized from the database and created from MRI images.

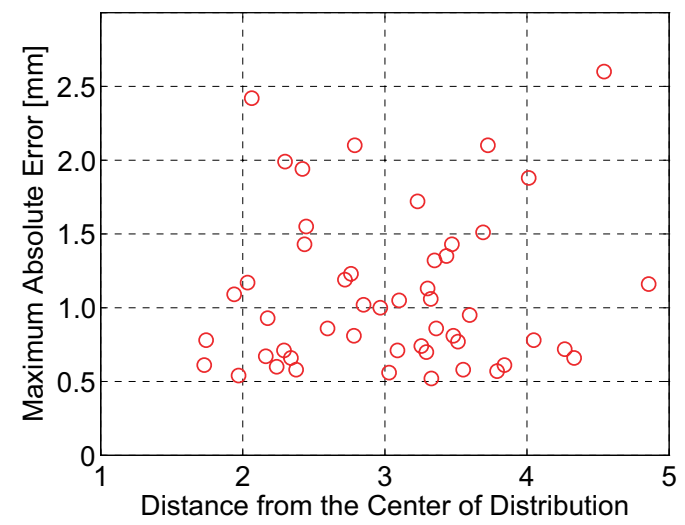

Fig. 9 Maximum absolute error against distance from the center of distribution.

\section{$5 \cdot 3$ 誤差の傾向}

最後に誤差の傾向をより詳細に検討する. 図 8 に提案手法で生成した 50 名分のモデルと MRI 画像から作成し たモデルの輪郭線を示す．同図 (a) が典型的な成功例である，皮膚表面と骨の双方について輪郭線がほぼ一致した. 
また，(b) が一見すると䛊差が大きいが関節の回転を考慮すると (a) と同程度の一致を実現できる例である. MRI 画像の撮像時には手指を自然に伸展させるように指示したが，稀に過伸展 (反り) 気味の姿勢をとる被験者がいた。 一方で代表寸法には反りに関する情報が含まれないためこのような不一致が生じると考えられる，以上のように， 無条件に，または姿勢の補正を行えば高い再現性を達成できる例が全体の 70\%強となった。これらの被験者につ いては最大誤差の平均が $1.0 \mathrm{~mm}$ 以下となった.

一方，(c)，(d)，(e) が部分的に一致しない例である。例えば (c) では爪近傍で，(d) では末節と中節の関節近傍 で，そして (e)では中節と基節の関節近傍でのみ誤差が大きくなる。このように，形状が局所的に一致しない例が 全体の $30 \%$ 弱，それらの最大誤差の平均は $1.5 \mathrm{~mm}$ 以下となった。これらの不一致も代表寸法には局所的な形状特 徵に関する情報が含まれないことに起因する。つまり，本手法では皮膚表面の明瞭な箇所から代表寸法を取得し， それをもとに重みの最適化を行っている，そのため，(d)，(e)のような内部形状は最適化において考慮されず，一 部の被験者の再現において不一致が生じる.

最後に，手指形状分布の中心からの距離に対する最大誤差を図 9 に示す。ただし中心からの距離とは分散で規 格化した主成分得点ベクトルの長さを表す。一般にこの值が大きい程, 分布の中心 (平均) から離れることになる. この分布の相関係数は 0.10 であり，距離の大小と最大誤差の大小にはほとんど相関がないことが分かる。これは 平均から離れた被験者程再現性が低くなる訳ではないことを示す。先に述べたように，これらの最大誤差の多く は指の内部構造の情報が代表寸法に含まれていないために生じる。レントゲンや超音波画像等の簡便な 2 次元医 用画像の取得により骨長を計測し精度を向上する事も可能だが，本手法では計測コストを考慮して皮膚表面のみ からの代表寸法取得を行った.

我々は手指のモデルとコンピュータシミュレーションを用いて, 工業製品の操作性や安全性の仮想的な検証を 行っている。このような用途を考えた時, 解析の精度を左右する最も重要な要素が指腹とその直上の骨の形状と なる。つまり (a)から (e)のような誤差の傾向であれば，現状での我々の用途には十分なモデルと言える。この意 味で提案手法で生成したモデルの多くが実用に足る物であった。

\section{6. 結 論}

ノギスのような簡便な道具で計測できる代表寸法值から形状特徵を重ね合わせ，骨まで含んだ個体別 3 次元手 指モデルを生成する手法を提案した．50名の成人男性について提案手法を適用した結果，皮膚表面だけでなく骨 まで含めた形状を抒おむ斿再現できた。 36 名の被験者については最大誤差の平均が $1.0 \mathrm{~mm}$ 以下となった。残りの 14 名の被験者については爪部，骨関節部において誤差が局所的に増大するが，それでも最大誤差の平均が $1.5 \mathrm{~mm}$ 以下であった。今後は工業製品の操作性や安全性を評価するための手指モデルの生成に利用する.

\section{文献}

（1）伊能教夫，鈴木和，槇宏太郎，宇治橋貞幸，“X 線 CT デー夕に基づく骨体の自動モデリング手法 (デラウニー分割を利用 した有限要素モデルの生成)”, 日本機械学会論文集 C 編, Vol. 68, No. 669(2002), pp. 1481-1486.

(2) M. Droske, B. Meyer, M. Rumpf and C. Schaller, “An adaptive level set method for medical image segmentation”, Lecture Notes in Computer Science, Vol. 2082(2001), pp. 416-422.

(3) T. M. Lehmann, J. Bredno and K. Spitzer, "On the design of active contours for medical image segmentation. a scheme for classification and construction ”, Methods of Information in Medicine, Vol. 42, No. 1(2003), pp. 89-98.

(4) B. Couteau, Y. Payan and S. Lavallee, “The mesh-matching algorithm: an automatic 3D mesh generator for finite element structures", Journal of Biomechanics, Vol. 33, No. 8(aug, 2000), pp. 1005-1009.

(5) L. Baghdadi, D. A. Steinman and H. M. Ladak, "Template-based finite-element mesh generation from medical images", Computer Methods and Programs in Biomedicine, Vol. 77, No. 1(2005), pp. 11-21.

(6) M. Tada, H. Yoshida, M. Mochimaru and T. Kanade, "Generating subject-specific FE models of fingertip with the use of MR volume registration”, In Proceedings of Eurohaptics 2006(2006), pp. 99-104. 
(7) 宮崎祐介, 宇治橋貞幸, 持丸正明, 河内まき子, “日本人の形態に基づいた頭部有限要素モデルの構築と衝撃シミュレー ション”, 日本機械学会論文集 A 編, Vol. 71, No. 704(2005), pp. 692-699.

(8) M. Mochimaru and M. Kouchi, “Statistics for 3D human body forms”, In Proceedings of SAE Digital Human Modeling for Design and Engineering(2000), pp. 2000-01-2149.

（9）持丸正明, 河内まき子, “適合メガネフレーム開発を目的とした 3 次元顔形状分類”, バイオメカニズム, Vol. 16(2002), pp. 88-99.

(10) 宮崎祐介, 宇治橋貞幸, 持丸正明, 河内まき子, “代表形状合成法による個体別頭部有限要素モデルの創成”, 日本機械学 会論文集 A 編, Vol. 71, No. 712(2005)，pp. 1646-1652.

(11) 多田充徳, 野原健, 梅田和昇, 持丸正明, “個体差の統計分析に基づく多様な形状特徵を持つ手指有限要素モデルの生成”, 日 本機械学会論文集 C 編, Vol. 75, No. 758(2009), pp. 2765-2772.

(12) K. Nohara, M. Tada, K. Umeda and M. Mochimaru, “Synthesizing Possible Variations of Finger Structure Using Principal Component Analysis for Non-Rigid Volume Registration Results”, In Proceedings of the 3rd International Symposium on Measurement, Analysis and Modeling of Human Functions(2007), pp.12-128. 